\title{
TECNOLOGIAS ASSISTIVAS PARA A COMUNICAÇÃO E A PARTICIPAÇÃO DE CRIANÇAS COM A SÍNDROME CONGÊNITA DO ZIKA VÍRUS
}

\author{
TECNOLOGÍAS DE ASISTENCIA PARA LA COMUNCACIÓN Y LA PARTICIPACIÓN \\ DE NINÕS COM SÍNDORME CONGÉNITA DEL VIRUS DEL ZIKA
}

\section{ASSISTIVE TECHOLOGIES FOR THE COMMUNICATION AND PARTICIPACION OF CHILDREN WITH CONGENITAL ZIKA VIRUS SYNDROME}

\author{
Marcia Denise PLETSCH ${ }^{1}$ \\ Miriam Ribeiro Calheiros de $\mathrm{SÁ}^{2}$ \\ Maíra Gomes de Souza da ROCHA ${ }^{3}$
}

RESUMO: Este artigo apresenta resultados sobre o uso de tecnologia assistiva para a comunicação e a participação de crianças com deficiência múltipla não oralizadas em decorrência da Síndrome Congênita do Zika Vírus (SCZV). A pesquisa abordou as concepções de profissionais da educação que atuaram com essas crianças nos anos de 2019 e 2020. Os dados foram coletados durante um Programa de Formação Continuada por meio de registros em plataforma online e portfólios formativos. Para fundar as análises, os referenciais da teoria bioecológica e sistêmica do desenvolvimento humano de Uri Bronfenbrenner foram empregados. Os resultados evidenciaram, entre outros aspectos, que usar recursos de tecnologia assistiva favorece a promoção da comunicação e, consequentemente, da participação, e, também, a escolarização dessas crianças, desde que se ofereça o apoio necessário, seja em casa ou na escola.

PALAVRAS-CHAVE: Tecnologias assistivas. Deficiência múltipla. Comunicação. Participação. Síndrome Congênita do Zika Vírus. Educação infantil.

RESUMEN: Este artículo presenta resultados sobre el uso de tecnología de asistencia para la comunicación y participación de niños no oralizados con discapacidades múltiples debido al sindrome congénito del virus del Zika (SCZV). La investigación abordó las concepciones las concepciones de los profesionales de la educación que trabajaron con estos niños en los

${ }^{1}$ Universidade Federal Rural do Rio de Janeiro (UFRRJ), Nova Iguaçu - RJ - Brasil. Professora Associada do Departamento Educação e Sociedade, do Programa de Pós-Graduação em Educação, Contextos Contemporâneos e Demandas Populares (PPGEduc) e do Programa de Pós-Graduação em Humanidades Digitais. Doutorado em Educação (UERJ). Bolsista de Produtividade em Pesquisa do CNPq - Nível 2. ORCID: https://orcid.org/00000001-5906-0487. E-mail: marciadenisepletsch@gmail.com

${ }^{2}$ Instituto Nacional de Saúde da Mulher, da Criança e do Adolescente Fernandes Figueira (IFF/FIOCRUZ), Rio de Janeiro - RJ - Brasil. Pesquisadora voluntária do grupo de pesquisa Estudos socioculturais do processo saúde-doença-cuidar e Professora colaboradora no Programa de Pós-Graduação stricto sensu Saúde da Mulher e da Criança IFF/Fiocruz. Pesquisadora do Observatório de Educação Especial e Inclusão Educacional (ObEE/UFRRJ). Doutorado em Saúde da Mulher e da Criança (IFF/Fiocruz). ORCID: https://orcid.org/00000002-3972-0377. E-mail: calheirosa@uol.com.br

${ }^{3}$ Secretaria Municipal de Educação (SEMED), Duque de Caxias - RJ - Brasil. Professora do Atendimento Educacional Especializado e Orientadora Pedagógica. Coordenadora Adjunta do Observatório de Educação Especial e Inclusão Educacional (ObEE/UFRRJ). Doutorado em Educação, Contextos Contemporâneos e Demandas Popu (UFRRJ). ORCID: https://orcid.org/0000-0001-7784-7259. E-mail: mairagsrocha@gmail.com 
años 2019 y 2020. Los datos fueron recolectados durante un Programa de Educación Continua a través de registros en una plataforma en línea y portafolios de capacitación. Para sustentar el análisis se utilizó como referencia la teoría bioecológica y sistémica del desarrollo humano de Uri Bronfenbrenner. Los resultados mostraron, entre otros aspectos, que el uso de recursos de tecnología de asistencia favorece la promoción de la comunicación $y$, consecuentemente, la participación, y también la escolarización de estos niños, siempre que se ofrezca el apoyo necesario, ya sea en casa o en la escuela.

PALABRAS CLAVE: Tecnologías de assistência. Discapacidad múltiple. Comunicación. Participación. Síndrome Congénito del Virus del Zika. Educación infantil.

ABSTRACT: This paper presents results on the use of assistive technology for the communication and participation of non-speaking children with multiple disabilities due to the Congenital Zika Virus Syndrome. The investigation addressed the conceptions of education professionals who worked with these children in 2019 and 2020. Data were collected during a Continuing Education Program through records on an online platform and training portfolios. To support the analysis, the references of the bioecological and systemic theory of human development by Uri Bronfenbrenner were used. The results showed, among other aspects, that the use of assistive technology resources favors the promotion of communication and, consequently, participation, and also the schooling of these children, provided that the necessary support and assistance are offered, whether at home or at school.

KEYWORDS: Assistive technologies. Multiple disability. Communication. Participation. Congenital Zika Virus Syndrome. Early childhood education.

\section{Introdução e aspectos teóricos}

Desde 2012, o Observatório de Educação Especial e Inclusão Educacional (ObEE) ${ }^{4}$ tem realizado um conjunto de pesquisas sobre a escolarização e o desenvolvimento de crianças com deficiência múltipla. Nos anos seguintes, com a epidemia do zika vírus, essas investigações se acentuaram, considerando que o Rio de Janeiro foi o segundo estado mais afetado pelo vírus com grande incidência na Baixada Fluminense, lócus prioritário de nossas investigações.

A deficiência múltipla causada pela Síndrome Congênita do Zika Vírus (SCZV) acometeu centenas de bebês cujas mães foram infectadas pelo Vírus da Zika durante a gestação, ocasionando, dentre outras peculiaridades de desenvolvimento, a microcefalia (DINIZ, 2016; LÖWY, 2019; PLETSCH; MENDES, 2020). A microcefalia é a complicação mais grave em crianças, mas a infecção do Zika Vírus também está associada a uma série de

4 O ObEE é vinculado ao Centro de Inovação Tecnológica e Educação Inclusiva (CITEI) do Instituto Multidisciplinar do Campus da UFRRJ de Nova Iguaçu. Disponível em: http://obee.ufrrj.br. Acesso em: 10 jul. 2021.

RIAEE - Revista Ibero-Americana de Estudos em Educação, Araraquara, v. 16, n. esp. 4, p. 2971-2989, dez. 2021. e-ISSN: 1982-5587 
outras condições, incluindo hipertonia, convulsões, anormalidades oftálmicas, artrogripose cardíaca e outras condições e atraso no desenvolvimento (FREITAS et al., 2020). Ou seja, a microcefalia provocada pela SCZV leva a uma combinação de deficiências (em geral, deficiência intelectual, visual e/ou motora) compatível aos quadros de deficiência múltipla, podendo afetar de diferentes formas o desenvolvimento, com desdobramentos diversos em sua qualidade de vida e nas relações com o meio (PLETSCH; ARAUJO; SOUZA, 2020; ROCHA, 2014; 2018; ROCHA; PLETSCH, 2015; 2018).

O Brasil foi o país mais severamente afetado dentre aqueles territórios que relataram surtos do Zika Vírus. Em 2018, havia 2.952 casos confirmados de SCZV no país, constituindo 79\% dos casos para a região de acordo com a Organização Panamericana de Saúde (OPAS) (PAHO/WHO, 2015). Estudos recentes identificaram distúrbios neurológicos, como atraso no neurodesenvolvimento, principalmente no domínio da linguagem, em crianças expostas ao Zika Vírus (ZV) que eram assintomáticas ao nascer (LOPES et al., 2018; PEÇANHA et al., 2021; VASCONCELOS et al., 2020). Ausência de sinais e sintomas ao nascer em bebês expostos não exclui que mais tarde na infância eles sejam verificados. A alta prevalência de casos assintomáticos no nascimento $(65$ a $83 \%)$ pode atrasar a identificação da associação entre síndromes congênitas (com ou sem início tardio) e infecção por ZV na mãe durante a gravidez. Os resultados destes estudos indicam que a longo prazo poderá ocorrer comprometimento cognitivo e sugere que crianças que são assintomáticas ao nascer, apesar de terem sido expostas ao ZV durante o período fetal, ainda podem ser suscetíveis a resultados adversos em seu desenvolvimento e em sua condição de saúde. Portanto, é fundamental a estruturação de redes intersetoriais envolvendo o sistema educacional, a saúde e a assistência social, para monitoramento integral dessas crianças, agora em idade escolar (LOPES et al., 2018; PINTO; FERNANDES; BARROS, 2021; SÁ; PLETSCH, 2021).

Para ampliar a participação educacional e social dessas crianças, assim como a sua qualidade de vida, um dos aspectos centrais evidenciado em nossas pesquisas é o oferecimento de suportes e recursos específicos, como os de tecnologias assistivas (TA's) que segundo a Lei Brasileira de Inclusão da Pessoa com Deficiência (LBI) - Lei nº 13.146/2015 caracterizam-se como "[...] produtos, equipamentos, dispositivos, recursos, metodologias, estratégias, práticas e serviços que objetivem promover a funcionalidade, relacionada à atividade e à participação da pessoa com deficiência ou com mobilidade reduzida, visando à sua autonomia, independência, qualidade de vida e inclusão social" (BRASIL, 2015, p. 2).

No caso de crianças com deficiência múltipla em decorrência da SCZV, recursos da tecnologia assistiva podem favorecer o desenvolvimento da comunicação, pois por se tratar, 
em sua maioria, de crianças não oralizadas, faz-se necessário o uso da comunicação alternativa por meio de pranchas ou recursos digitais em tablets na promoção da comunicação, da autonomia e da participação nas suas escolhas na vida cotidiana e escolar. Como sinalizado por Rocha (2018) e Sá e Pletsch (2021), a comunicação alternativa (CA) é entendida como integrante da área de tecnologia assistiva, podendo envolver desde gestos e expressões faciais a diversas formas gráficas, como modo de efetuar a comunicação de pessoas que não conseguem utilizar a linguagem verbal. Ainda, considera os propósitos de promover e suplementar a fala e de garantir uma nova alternativa de comunicação, caso não haja a possibilidade de desenvolvê-la.

Os recursos de tecnologia assistiva são organizados ou classificados de acordo com objetivos funcionais aos quais se destinam, podendo ser motoras ou sensoriais (BERSCH, 2008; ROCHA, 2014, 2018). Para promover a comunicação de crianças que não falam ou até mesmo a escrita funcional são, geralmente, utilizadas pranchas de comunicação e até softwares como, por exemplo, o Boardmaker, disponível nas salas de recursos multifuncionais do Atendimento Educacional Especializado (AEE), oferecido no contraturno da escolarização de forma complementar para alunos com deficiências e portadores do Transtorno do Espectro do Autismo (TEA) e, de forma suplementar, para alunos com altas habilidades/superdotação (BRASIL, 2009).

O conceito de funcionalidade humana tem sido indicado para a avaliação da deficiência e está previsto na LBI (BRASIL, 2015). Numa perspectiva biopsicossocial, a avaliação da deficiência, segundo a LBI, considera: os impedimentos nas funções e nas estruturas do corpo; os fatores socioambientais, psicológicos e pessoais; a limitação no desempenho de atividades; e a restrição de participação. A origem da funcionalidade como premissa para a compreensão do fenômeno da deficiência ocorreu em 2001, com a Classificação Internacional de Funcionalidade, Incapacidade e Saúde - CIF (WHO, 2007). A CIF compreende a funcionalidade a partir da interação dinâmica entre problemas de saúde, fatores contextuais pessoais e ambientais. É o que denominamos de modelo biopsicossocial.

No modelo biopsicossocial, a deficiência não é mais compreendida como um atributo da pessoa, mas como resultado da interação social e das barreiras existentes. Essa perspectiva nos remete para uma abordagem focada nas possibilidades dos sujeitos e nas expectativas deles e de seus familiares. Por isso, temos defendido uma ampla interação entre os profissionais da educação e da saúde que atuam com crianças com a SCZV e suas famílias, no estabelecimento de ações e estratégias que proporcionem o desenvolvimento da funcionalidade das mesmas na escola e em casa (SÁ; PLETSCH, 2021). Para tal, uma das 
possibilidades de atuação é a proposta das F Words, desenvolvidas pelo grupo da CanChild no Canadá, que traduzido para o português significa Minhas Palavras Favoritas (Funcionalidade, família, saúde, amigos, diversão e futuro). As F Words foram introduzidas em 2011, a partir de um estudo de Rosenbaum e Gorter (2012), baseando-se na estrutura da CIF, com o objetivo de promover o desenvolvimento integral de crianças com deficiência em que nenhum dos atores envolvidos na intervenção pode ser visualizado de maneira isolada, incluindo as famílias.

Os autores destacam que as F Words realmente ajudam as pessoas que trabalham com crianças com deficiência e suas famílias a compreenderem os problemas enfrentados por elas na vida real. A partir desse estudo, desenvolveram-se orientações para trabalhar as palavras favoritas, com as famílias, profissionais da saúde e, mais recentemente, uma abordagem voltada às escolas. Para as escolas, a proposta é que os professores possam trabalhar com as outras crianças da turma, de maneira que elas entendam melhor seu colega com deficiência, favorecendo, assim, a participação da criança com deficiência nas atividades realizadas na escola. A figura a seguir sistematiza essa abordagem.

Figura $1-F$ Words elaborado a partir das CIF

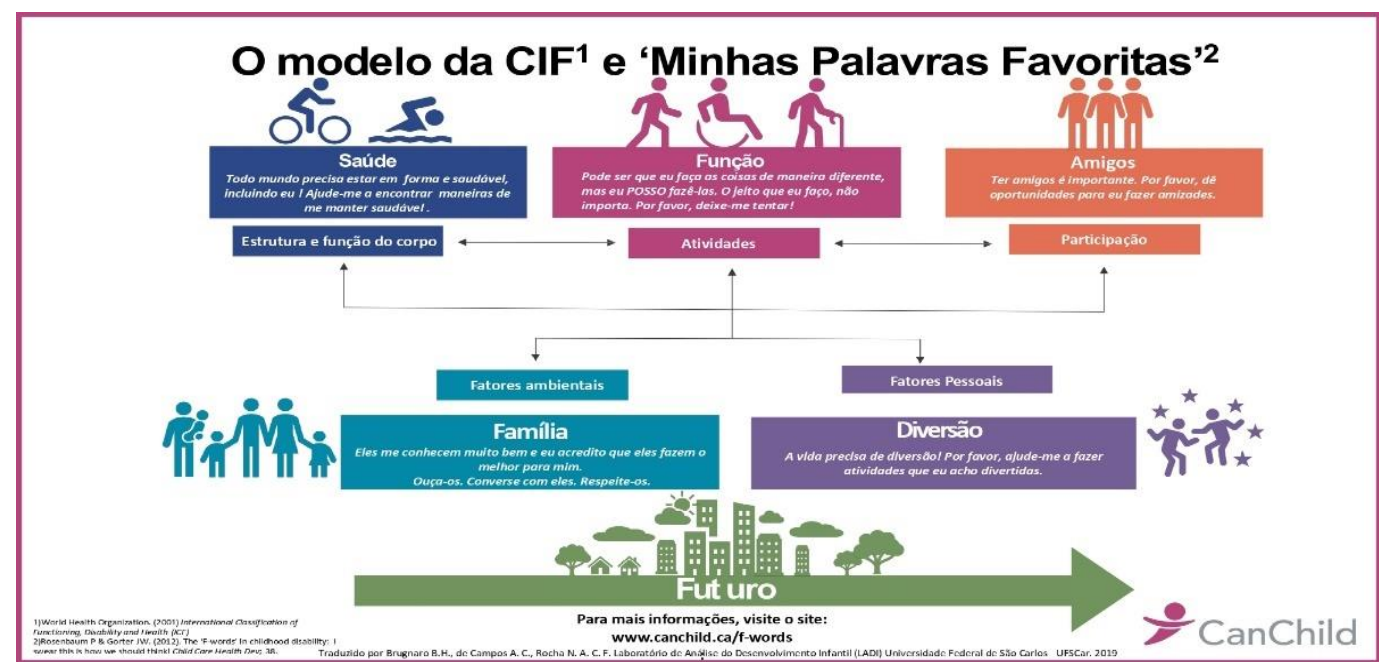

Fonte: CanChild (2012)

Nessa perspectiva, um dos conceitos centrais é o de participação, o qual é complexo e polissêmico e pode ser analisado de diferentes formas. Na CIF, a participação é definida como “envolvimento em toda situação de vida", incluindo a vida familiar, escola e comunidade, sendo crucial para as crianças com deficiência porque afeta diretamente o seu bem-estar, as relações sociais, a saúde mental e física. Juntamente com a atividade, o ambiente é determinante chave para a promoção dessa participação. Aqui, destacamos que é muito 
importante que a criança possa ser criança, que possa brincar, ter momentos de diversão e de compartilhamento de experiências com outras crianças. Por isso, é fundamental conhecer o que a criança gosta para pensar formas de tornar as atividades acessíveis para a sua participação. Isso ajuda a criança a construir confiança e um senso de capacidade. Cabe, aqui, clarificar os conceitos de capacidade e desempenho, a saber: a capacidade é o que podemos fazer da melhor forma, enquanto desempenho é o que normalmente fazemos. Ora, sabemos que o desempenho melhora com a prática e, portanto, nossa ênfase primária deve ser na promoção de atividades (ROSENBAUM; GORTER, 2012). Sabemos que muitas crianças com deficiência podem ser privadas de experiências, e isso pode ser associado não apenas à sua condição de saúde, mas também à falta de oportunidades e de acesso a um ambiente que facilite tal possibilidade.

Neste artigo, a ênfase será a participação na escola, incluindo atividades não estruturadas (por exemplo, amizades, brincadeiras), organizadas (por exemplo, esportes e brincadeiras no recreio, artes) e em sala de aula (por exemplo, trabalho em grupo, realização das tarefas). Em recente revisão sistemática de 1828 artigos, Maciver et al. (2018) sinalizaram que a participação de crianças com deficiência é restrita na escola em comparação com a dos seus pares, o que pode acarretar consequências significativas ao longo da vida para o desempenho, a qualidade de vida e o seu bem-estar. Ou seja, os alunos com deficiência (no caso, com deficiência múltipla) acabam participando menos das atividades estruturadas e não estruturadas na escola, aspecto que afeta a sua experiência e interação social. Nas palavras de Maciver et al. (2018, p. 23), a participação na escola pode ser assim sistematizada:

A participação escolar inclui atividades ativas e significativas (de uma perspectiva pessoal ou socioeconômica) que são necessárias ou desejadas para cumprir o papel do aluno dentro ou fora do contexto escolar. A participação na escola não é apenas atividade em sala de aula, trabalho escolar ou realização. A participação inclui eventos escolares, viagens, esportes, artes e relacionamentos com adultos e amizades com colegas. A participação escolar pode ser entendida em termos de quanto, com que frequência e quais atividades a criança faz (frequência), bem como sua experiência subjetiva (envolvimento) ${ }^{5}$.

No Brasil, o conceito de participação na escola é pouco utilizado para orientar práticas pedagógicas baseadas em evidências e mais eficazes. De maneira geral, o conceito é discutido à luz de princípios contidos em documentos oficiais que definem a inclusão educacional como acesso, participação e aprendizagem (BRASIL, 2008). Essa discussão é centrada no modelo social de deficiência, que tende a focar a participação dessas pessoas pelo ângulo dos direitos

${ }^{5}$ Tradução do original em inglês realizada por Márcia Denise Pletsch.

RIAEE - Revista Ibero-Americana de Estudos em Educação, Araraquara, v. 16, n. esp. 4, p. 2971-2989, dez. 2021. e-ISSN: 1982-5587 
políticos e civis, mas não como ela afeta o funcionamento humano, a aprendizagem e o desenvolvimento dos indivíduos. Granlund et al. (2012), em estudo realizado na Suécia, constataram que os documentos políticos apresentam o conceito de participação, focando muito mais em aspectos relativos à acessibilidade do ambiente escolar do que à experiência subjetiva de envolvimento efetivo em atividades escolares.

Por exemplo, em crianças com deficiência, sobretudo naquelas com deficiências múltiplas mais severas, as habilidades funcionais são elementos que podem afetar a sua participação nas atividades em casa ou na escola, as quais, segundo Maxwell and Koutsogeorgou (2012), incluem fazer a atividade e se envolver com tal experiência. De acordo com os mesmos autores, o envolvimento nas atividades escolares é maior quando o pensar e o fazer coincidem. Para tal, é necessário promover o desenvolvimento da comunicação da criança de forma a estruturar a linguagem e o pensamento por meio da apropriação do sistema simbólico, como já evidenciado em nossas pesquisas anteriormente (ROCHA; PLETSCH, 2018; SÁ; PLETSCH, 2021). Isto é, a comunicação alternativa é um instrumento que o sujeito utiliza como mediador entre si e o mundo ao seu redor para se comunicar, expressar seus sentimentos e desejos. Por isso, ao não promovermos a comunicação por meio de recursos alternativos, a participação desses sujeitos fica prejudicada. Além disso, a sua autonomia para escolher quando e como participar acaba não se desenvolvendo.

Isso quer dizer que, para a escolarização de crianças com deficiência múltipla sem comunicação verbal, é necessário oferecer recursos que podem implicar o uso de instrumentos desde os mais simples, feitos artesanalmente, até os mais tecnologicamente complexos e de alto custo. Os recursos podem ser classificados conforme sua densidade tecnológica (baixa, média ou alta), como inclusive indica a própria CIF. Como exemplos, de baixa tecnologia podemos mencionar as pranchas de comunicação artesanais, de média tecnologia as pranchas sonorizadas com uso do computador e de alta tecnologia podemos citar mecanismos de comunicação que usam sensor infravermelho acoplado a óculos e computador, como era o usado pelo físico Stephen Hawking.

Independentemente do recurso disponível a ser utilizado, é necessário focar na funcionalidade da criança, por meio de observação e escuta atenta dos profisssionais e familiares envolvidos no cuidado da criança para uma avaliação efetiva de suas necessidades. Para isso, é fundamental garantir, além dos recursos materiais, recursos humanos como suportes ou apoios nesse processo. Estes incluem todos os profissionais e cuidadores que, no caso de crianças com a SCZV, tem se centrado na mãe, conforme evidenciaram várias 
pesquisas (AZEVEDO; FREIRE; MOURA, 2021; FLEISCHER; LIMA，2020; LIMA; SOUZA, 2021; MENEZES et al., 2018; PLETSCH; MENDES, 2020). Promover programas de intervenção e comunicação alternativa tendo como centralidade a família (ou nesse caso a mãe), considerando a rotina e a realidade social da criança, tem se mostrado promissor na literatura científica internacional (ROSENBAUM; GORTER, 2012).

Ainda em termos teóricos empregamos os referenciais da teoria bioecológica e sistêmica do desenvolvimento humano de Uri Bronfenbrenner. Essa teoria defende que a interação entre diversos fatores (criança, família e ambiente social/comunitário) e a qualidade dessas relações favorecem o desenvolvimento infantil a partir de quatro núcleos: a pessoa, o processo, o contexto e o tempo. De acordo com Bronfenbrenner, o desenvolvimento humano envolve uma série de fatores que estão interrelacionados às características pessoais de cada um desde o nascimento, as quais são transformadas, de acordo com o contexto e a realidade social e cultural em que cada pessoa vive. A figura a seguir sistematiza a teoria de Bronfenbrenner mostrando o dinamismo e a interrelação entre os núcleos que a constituem.

Figura 2 - Síntese da teoria bioecológica de Bronfenbrenner

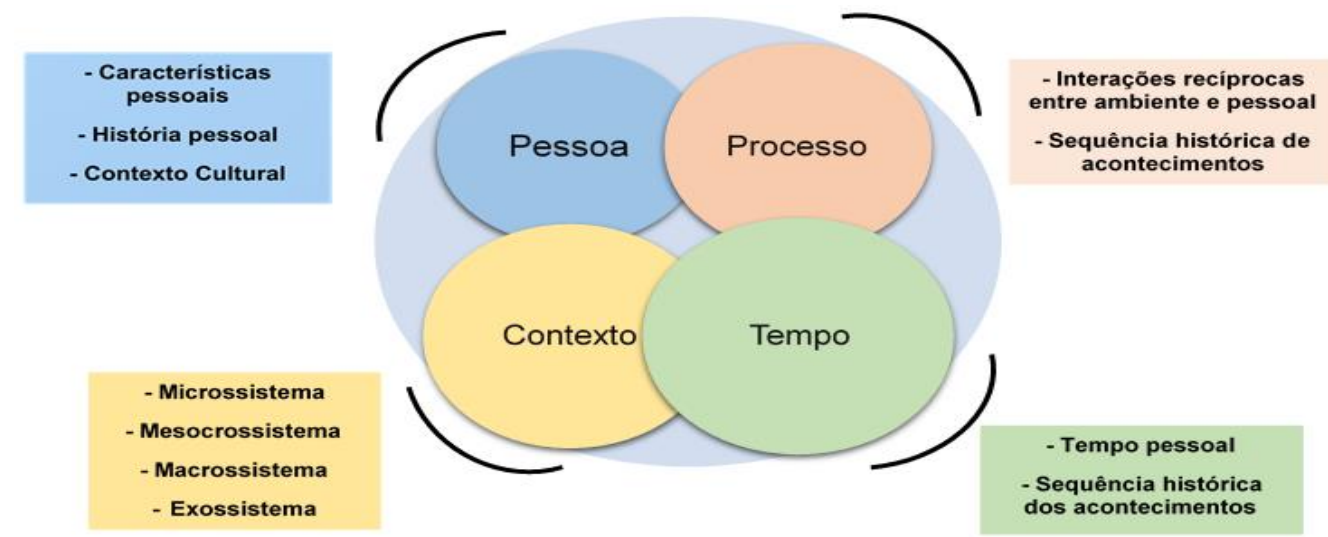

Fonte: Elaborado a partir de Bronfenbrenner (2012)

Lembramos que o microssistema se caracteriza pelo ambiente direto em que a pessoa vive experiências pessoais na família, escola, creche. O mesocrossistema ocorre quando há interrelações e influências recíprocas entre dois ou mais ambientes nos quais a pessoa participa ativamente. Já o macrossistema inclui elementos do sistema que não envolvem a pessoa como um participante ativo, mas nos quais ocorrem eventos que afetam aquilo que acontece em um dos microssistemas, e o exossistema é formado pelo padrão global de ideologias, crenças, valores, religiões, formas de governo, culturas e subculturas presentes no cotidiano das pessoas (BRONFENBRENNER, 2012; SÁ; PLETSCH, 2021). 
A partir destas premissas apresentamos resultados de uma investigação sobre o uso de recursos de tecnologias assistivas para a promoção da comunicação e a participação de crianças com SCZV a partir das concepções de profissionais de educação. Importante mencionar que a chegada destas crianças na escola ainda é pouco investigada, pois em sua maioria os estudos até então desenvolvidos foram na área da saúde e da assistência social (VIANA, 2021). Neste sentido, este artigo traz contribuições importantes sobre os caminhos e possibilidades para a escolarização das mesmas.

\section{Procedimentos éticos e metodológicos da pesquisa}

A pesquisa foi realizada durante a execução de um Programa de Formação Continuada que integra um projeto multidisciplinar, aprovado pelo Protocolo de ética 135/2021, processo $n^{\circ}$ 23083.031153/2019-40, estruturado em três eixos, a saber: 1) criança e família; 2) escola e professores; 3 ) intersetorialidade, nos quais tem sido desenvolvido um conjunto de estudos e ações intersetoriais entre educação, saúde e assistência social na promoção da escolarização e do desenvolvimento integral de crianças com SCZV na Baixada Fluminense (PLETSCH, 2018; 2019). O projeto é constituído por cerca de 50 pesquisadores da Universidade Federal Rural do Rio de Janeiro (UFRRJ), da Universidade do Estado do Rio de Janeiro (UERJ), da Pontifícia Universidade Católica do Rio de Janeiro (PUC-Rio), da Universidade do Estado de Santa Catarina (UDESC) e da Fundação Oswaldo Cruz (FIOCRUZ) com integrantes da Escola Nacional de Saúde Pública (ENSP) e do Instituto Fernandes Figueira (IFF).

O Programa de Formação Continuada para 50 profissionais de Educação foi desenvolvido em uma rede Municipal de Ensino da Baixada Fluminense, no Rio de Janeiro. Participaram professores de turmas comuns da Educação Infantil, professores do Atendimento Educacional Especializado (AEE), orientadores educacionais, coordenadores pedagógicos, diretores escolares e agentes de apoio à inclusão ${ }^{6}$ da área da saúde e da educação. Importante dizer que parte dos resultados deste Programa foram publicados em artigo anterior (PLETSCH; ARAÚJO; ROCHA, 2020).

Com duração de 120 horas, o Programa iniciou em formato presencial, mas em função da pandemia mundial provocada pelo novo "coronavírus" (SARS-CoV-2), declarada pela Organização Mundial da Saúde em 11 de março de 2020, passou a ser desenvolvido em formato online com atividades síncronas via plataforma Zoom e assíncronas via plataforma

\footnotetext{
${ }^{6}$ Essa é a nomenclatura utilizada pela Rede de Ensino em questão para os profissionais que atuam como suporte humano e mediador nos processos de ensino nas turmas comuns, auxiliando também nas necessidades de autonomia e nos cuidados essenciais de alunos que apresentem esse tipo de demanda.
} 
digital online do Facebook, no período de fevereiro de 2020 a outubro de 2020, conforme amplamente discutido por Pletsch, Araújo e Rocha (2020).

Todos as fases do Programa foram estruturadas de forma colaborativa com a equipe gestora da Rede Municipal participante, tomando como base as demandas apresentadas pelas equipes escolares que receberam em suas turmas de Educação Infantil, nos anos de 2019 e 2020, crianças com a SCZV, em diálogo com as Diretrizes Curriculares Nacionais para a Educação Infantil de 2009 (DCNEI) - Resolução nº 5, de 17 de dezembro de 2009 (BRASIL, 2009), considerando dez eixos, a saber: 1) Conhecendo a realidade; 2) Postura, movimento e alimentação; 3) Interação e Comunicação; 4) Brincadeiras; 5) Direto a Aprender; I) 6 Direito a Aprender II; 7) Colaboração e Intersetorialidade; 8) Planejamento Educacional Individualizado (PEI); 9) Família; 10) E agora? A vida continua (BANCO DE DADOS DO OBEE, 2019-2020).

Durante o Programa foram empregados diferentes procedimentos para sistematizar/estruturar os dados: questionários presenciais e online, entrevistas semiestruturadas online, registros na plataforma digital online do Facebook e portfólios com os registros dos participantes sobre o seu próprio processo formativo. Para este artigo usaremos somente os dados contidos nos portfólios e registros digitais online realizados pelos participantes durante atividades assíncronas.

Para a análise dos dados os referenciais de Bronfenbrenner foram importantes para discutir as concepções dos participantes do Programa de Formação Continuada sobre o uso de recursos de tecnologias assistivas, sejam de baixo ou alto custo, na promoção da comunicação e da participação das crianças com a SCZV nas atividades educacionais.

\section{Tecnologias assistivas, comunicação e participação de crianças com SCZV}

Os dados da investigação revelaram, desde o início, a ansiedade dos professores e demais profissionais em receber em suas escolas crianças com deficiência múltipla em decorrência da SCZV. Aliás, a falta de conhecimentos dos professores com a chegada destas crianças em turmas comuns de ensino, as que chamamos turmas inclusivas, tem sido uma constante em nossas investigações (PLETSCH, 2015; ROCHA, 2014; 2018). Durante as atividades do Programa de Formação Continuada ficou claro que as professoras e as demais profissionais da educação não questionam a chegada das crianças em suas turmas, mas sinalizavam falta de conhecimentos sobre como deveriam atuar, principalmente para promover a comunicação e a interação dessas crianças com as demais da turma. Para ilustrar 
como as participantes do Programa foram se apropriando de novas estratégias e conceitos sobre linguagem e comunicação, destacamos o trecho a seguir, extraído do portfólio formativo de uma das professoras:

Aprendi que o ato de se comunicar é abrangente e que não pode ser resumido à aquisição da linguagem, que gestos, expressões faciais e até mesmo olhares, podem demonstrar sentimentos e posicionamentos, sem que haja nenhuma utilização de sons. Participar das atividades do Programa me proporcionou que a ausência da linguagem ou a linguagem deficiente não é um impeditivo para que o sujeito se comunique. É necessário observar as condições que cada sujeito apresenta e estimular tanto a comunicação quanto a aprendizagem, por isso é importante termos em mente com outras formas de comunicação que atendam às necessidades de cada aluno. A partir do texto "O eu e o outro: construímos conhecimentos sobre a comunicação através do tato". Primeiro nos foram apresentados conceitos e as classificações da deficiência múltipla e o que esses indivíduos têm em comum. Também aprendemos sobre a diferença entre comunicação alternativa e comunicação alternativa tátil. Ficou claro que podemos construir nosso material pedagógico de comunicação alternativa a partir da realidade dos nossos alunos (Professora de Educação Infantil que tem uma criança com SCZV, registro realizado no primeiro semestre de 2020).

Como podemos depreender do trecho coligido, a Professora registrou um conjunto de aprendizagens que entende serem necessárias para trabalhar com a sua aluna com a SCZV, principalmente, sobre linguagem e os diferentes modos de comunicação. A este respeito, durante o Programa as participantes mostraram que precisavam rever a sua compreensão sobre a linguagem como uma categoria vinculada apenas à comunicação verbal. Os dados registrados na plataforma digital mostram que as atividades síncronas e assíncronas desenvolvidas ampliaram essa compreensão considerando a fala, a escrita, o desenho, símbolos, símbolos táteis, gestos, expressões faciais e o uso de recursos de comunicação alternativa elaborados de forma individualizada com imagens e fotografias ou por meio de programas previamente existentes, como é o caso do Boardmaker, aqui citado. Sobre tal aspecto, o registro em portfólio formativo mostra esse entendimento: "nos expressamos de várias formas, não somente com a linguagem oral, dessa forma as crianças com deficiência podem se comunicar pelos atos comunicativos, como: olhar, vocalização, verbalização, gestos, grito, raiva e choro, formando um conjunto de hábitos comunicativos entendido pelos familiares e por quem convive de perto com essas crianças" (Registro em Portfólio, segundo semestre de 2020). Para Marçal (2018), quando se reconhece a linguagem e seus diferentes modos de expressão verbais, visuais, táteis, digitais, corporais, também se constrói associações complexas entre palavras, ações e conceitos, que por sua vez são formados na interação com o meio e com o outro. 
Ficou evidenciado, também, nos registros na plataforma online, que as professoras compreenderam que a falta de comunicação em crianças com deficiência múltipla pode levar ao seu isolamento na sala de aula e, consequentemente, prejudicar sua participação nas atividades e o seu desenvolvimento educacional e social. Também registraram que a interação pelo olhar com a criança, o uso de recursos, objetos ou símbolos táteis podem ser usados para introduzir formas iniciais de comunicação, sempre respeitando as indicações científicas já validades. Uma das professoras chegou a relatar que "o uso de materiais e recursos de tecnologia assistiva podem ser uma oportunidade de explorar a funcionalidade comunicativa, pois, tenho casos de alunos em que o feedback se dá com o movimento dos olhos e expressão facial, de partes do antebraço, e não das mãos, como habitualmente estamos acostumados" (Registro em portfólio formativo de uma professora que atua com crianças com deficiência múltipla severa, segundo semestre de 2020).

A importância da interação pelo olhar foi registrada por Sá e Pletsch (2021) durante pesquisa que analisou a participação de crianças com SCZV em atividades em casa. As pesquisadoras mostraram que as mães que participaram do estudo relataram que conhecem seus filhos não apenas pelo olhar e pelo sorriso, mas também pela forma como choram. As autoras também sinalizaram a importância do envolvimento delas na promoção de programas de comunicação alternativa. Os indícios presentes na forma de comunicação aqui registrados não podem ser ignorados, principalmente por estarmos discutindo aspectos da escolarização de crianças com deficiência múltipla severa, não oralizadas. Rocha (2018) em sua tese de doutorado mostrou a necessidade de reconhecimento de pequenos gestos, inclusive por meio do olhar, como ponto de partida para introduzir recursos de comunicação alternativa, como o uso de cartões contendo, por exemplo, a escolha dos alimentos, e a indicação por meio do piscar para mostrar o entendimento da criança sobre o significado do sim ou do não sobre o que deseja comer.

A relação entre os agentes de dois diferentes microssistemas (escola e família) segundo a perspectiva bioecológica é fundamental, pois amplia as possibilidades de apropriação pelas crianças dos símbolos e estratégias empregadas e seu consequente desenvolvimento. Pouco adianta usar determinadas estratégias no cotidiano familiar da criança e usar outros mais estruturados na escola. Isso acaba, muitas vezes, confundindo a criança. Uma das professoras registrou em seu portfólio formativo que "acho importante a integração de todos escola e família para um bom desenvolvimento dessas técnicas de comunicação. Assim, todas as ferramentas utilizadas para esse desenvolvimento serão usadas 
sempre e o aluno desenvolve melhores resultados" (Registro em portfólio formativo, segundo semestre de 2020). Outra professora seguiu na mesma direção ao dizer que:

Precisamos estar conectados para que o trabalho com a criança tenha êxito. Estamos envolvendo os pais na comunicação alternativa, partilhamos figuras para que o trabalho com o aluno não seja fragmentado. A escola não deve fazer um trabalho isolado, por isso precisamos da participação da família nesse processo (Registro em plataforma digital de uma professora que atua na Educação Infantil com uma criança com SCZV, primeiro semestre de 2021).

Esses relatos indicam que a perspectiva bioecológica, usando os referenciais da proposta de $F$ Words de Rosenbaum e Gorter (2012), baseada na estrutura da CIF, que propõe a atuação conjunta com os familiares das crianças com deficiência, é uma iniciativa importante e necessária para o desenvolvimento da mesma. A nossa pesquisa verificou, ainda, que a participação das famílias e o oferecimento de atividades interativas em sala de aula entre as crianças, não apenas para favorecer a sua comunicação e participação, acaba ampliando a sua inclusão escolar e social. Para tal, o trabalho colaborativo entre a professora da turma comum de ensino, o professor da sala de recursos multifuncionais e o agente de apoio à inclusão foram destacados como essenciais nesse processo.

Outro aspecto que as participantes do projeto informaram foi que a introdução de estratégias e até mesmo de cartões de comunicação durante as brincadeiras se caracteriza como uma iniciativa promissora. Por exemplo, para brincar a criança precisa selecionar de alguma forma, seja pelo olhar ou pela inclinação da cabeça ou corpo, o cartão com o símbolo brincar. Na Educação Infantil, a brincadeira faz parte das atividades desenvolvidas com as crianças para que se apropriem de diferentes conceitos e processos psicológicos superiores, como atenção, concentração, memória, seriação, classificação, entre outros, de forma interativa com os coleguinhas de turma. É também nesse nível educacional que são promovidas ações para que a criança participe, explore, expresse e se conheça. A pesquisa de Fernandes, Santos e Mercado (2019), realizada com mães, evidenciou como o brincar se mostrou importante para o desenvolvimento de crianças com deficiência múltipla em decorrência da SCZV. Os dados da pesquisa revelaram que a brincadeira e os brinquedos foram importantes no desenvolvimento das duas crianças que participaram da investigação. A brincadeira por meio da mediação de um adulto contando histórias também foi avaliada como positiva no desenvolvimento da comunicação em crianças com autismo (DELIBERATO; ADURENS; ROCHA, 2021). Fica aqui evidenciado que introduzir ainda na Educação Infantil estratégias de comunicação alternativa tendo como eixo central o brincar (que envolve 
recursos de baixo custo) pode ser uma iniciativa potencializadora para a promoção da comunicação e da participação das crianças nas atividades escolares.

Para uma das professoras: "com certeza, as brincadeiras e brinquedos são excelentes para todas as crianças, principalmente porque aproximam as crianças e favorecem a comunicação, na relação adulto-criança, criança-criança” (Registro em plataforma online, segundo semestre de 2020). Ainda sobre as estratégias usadas, uma professora relatou que tem em sua sala de aula "uma caixa sensorial contendo diferentes materiais, com variadas texturas, formas, cores, funcionalidades, para exploração da criança e fico atenta as observações para mediar (o olhar, encostar, mão sobre mão, movimento de pegada, apontar)" (Registro em plataforma online, segundo semestre de 2020).

Corroborando com essa fala, trazemos a referência da pesquisa de Marçal (2020), que aproxima saberes das áreas de design, saúde e educação, e permitiu o fortalecimento de ações visando diminuir barreiras, dentre elas as comunicacionais, através dos brinquedos construídos especificamente para as necessidades sensoriais e comunicacionais das crianças, ou como denominado pela autora, os "objetos sensíveis". Essa experiência permitiu a consolidação de práticas inclusivas por meio da mediação - pelo brinquedo - das relações entre os sujeitos, com base no lugar de potência das crianças com deficiência. É o que a autora define como modos diversos de interação.

Ainda sobre as brincadeiras e usos de objetos pedagógicos destacamos o projeto "Caixa e Bacia", desenvolvido de maneira multidisciplinar, visando a construção de recursos de estimulação para crianças de 0 a 3 anos com a SCZV, descrito por Marçal (2019). Neste projeto, de acordo com a autora, partiu-se do entendimento de que é no ato do brincar que a criança descobre o espaço, o tempo, experimenta sensorialidades, constrói consciência do corpo e descobre diferentes formas de se expressar. Também se entendeu que é por meio do corpo em movimento e interação que a criança percebe o mundo e constrói linguagem corporal e comunicação não-verbal. Isto é, percebe que o corpo se expressa. O uso de objetos pedagógicos ou brinquedos, neste caso em miniatura, também foi destaque na pesquisa de Moreira (2021), no desenvolvimento da comunicação alternativa tátil para crianças com deficiência múltipla sensorial visual.

Outro ponto destacado pelas professoras sobre as estratégias para introduzir e usar a comunicação alternativa com crianças com SCZV é que é preciso ficar atento às necessidades de cada criança. O trecho a seguir mostra a preocupação de uma das professoras sobre essa questão: 
Na escolha das categorias, considero que o ideal é avaliar a necessidade de cada aluno e, assim investir naquilo que ele responde melhor. Sempre usei a $C A$, mas vejo que ela precisa ser reinventada para cada aluno, em cada aula. Verificar quais são as dificuldades de abstração, quais os canais sensoriais que respondem, se é necessário utilizar algum outro recurso de tecnologia assistiva para dar suporte. Esses recursos e estratégias funcionam como instrumentos de compensação das limitações apresentadas, colaborando nos processos de ensino e aprendizagem dessas crianças (Registro em plataforma online de uma orientadora educacional, segundo semestre de 2020).

Refletindo sobre os extratos dos portfólios e registros na plataforma digital, destaca-se a importância dada pelos sujeitos da pesquisa ao envolvimento das crianças em atividades e participação no espaço escolar a partir de atividades lúdicas, usando a brincadeira como estratégia. Nas palavras da Professora Maria, "a brincadeira pode favorecer a convivência, a participação, a exploração, a expressão, o conhecer-se. É muito importante para nossas crianças com alguma deficiência experimentar todos esses aspectos no período da Educação Infantil" (Registro no portfólio, segundo semestre letivo de 2020). Isso evidencia que os professores em suas práticas, no nível do ambiente social, segundo o modelo de Bronfenbrenner, reconhecem a importância do oferecimento de oportunidades de participação numa perspectiva inclusiva, promovendo uma experiência com todas as crianças da sala de aula.

Em síntese, a pesquisa indicou que o desenvolvimento da comunicação alternativa pode ocorrer com qualidade por meio de tecnologia assistiva de baixo custo, associada a estratégias participativas que valorizem o uso de brinquedos e objetos pedagógicos em sala de aula, comumente existentes na Educação Infantil. Em outros termos, é possível desenvolver a comunicação utilizando recursos e atividades lúdicas, a fim de estimular a participação das crianças com SCZV nas atividades escolares de maneira mais significativa, dando, assim, mais qualidade à sua inclusão educacional. Igualmente, o estudo mostrou que a teoria bioecológica de Bronfenbrenner (2012), articulada com a proposta de F Words elaborada por Rosenbaum e Gorter (2012), fornece subsídios importantes para a elaboração de estratégias que fomentem a comunicação e a participação de crianças com deficiência múltipla não oralizadas em decorrência da SCZV. Adicionalmente, esta investigação sugere que a atuação colaborativa entre professores, profissionais de apoio (sejam da educação ou da saúde) e familiares é central para a aprendizagem escolar e melhoria da qualidade de vida dessas crianças. 
AGRADECIMENTOS: Agradecemos o financiamento do Conselho Nacional de Desenvolvimento Científico e Tecnológico (CNPq- proc. 307492/2018-4) e Fundação de Amparo à Pesquisa do Estado do Rio de Janeiro (FAPERJ) por meio do Programa Jovem Cientista do Nosso Estado e Edital Grupos Emergentes (proc. 202.734/2018 e proc. 010.002186/2019, respectivamente). Também agradecemos a doutoranda Izadora Souza no apoio à elaboração da figura 2.

\section{REFERÊNCIAS}

AZEVEDO, C. DA S.; FREIRE, I. M.; MOURA, L. N. de F. “Aí começou a saga...”: fragilidade psicossocial na epidemia do vírus Zika. Cad. Saúde Pública, v. 37, n. 7, jul. 2021. DOI: https://doi.org/10.1590/0102-311X00121420

BERSCH, R. Introdução à Tecnologia Assistiva. Porto Alegre, RS: CEDI - Centro Especializado em Desenvolvimento Infantil, 2008.

BRASIL. Ministério da Educação. Secretaria de Educação Continuada, Alfabetização, Diversidade e Inclusão. Política Nacional de Educação Especial na perspectiva da Educação Inclusiva. Brasília, DF: MEC/SECADI, 2008.

BRASIL. Resolução n. 4, de 02/10/09. Institui Diretrizes Operacionais para o AEE na Ed. Básica, modalidade Educação Especial. Brasília, 25 ago. 2009. Disponível em: http://portal.mec.gov.br/dmdocuments/rceb004_09.pdf. Acesso em: 10 jul. 2021.

BRASIL. Lei n. 13.146, de 6 de julho de 2015. Institui a Lei Brasileira de Inclusão da Pessoa com Deficiência (Estatuto da Pessoa com Deficiência). Diário Oficial da União: Seção 1, Brasília, DF, n. 127, p. 2-11, 7 jul. 2015.

BRONFENBRENNER, U. Bioecologia do desenvolvimento humano: tornando os seres humanos mais humanos. Porto Alegre, RS: Artmed, 2012.

DELIBERATO, D.; ADURENS, F. D. L.; ROCHA, A. N. D. C. Brincar e contar histórias com crianças com Transtorno do Espectro Autista: mediação do adulto. Revista Brasileira de Educação Especial, v. 27, 2021. DOI: https://doi.org/10.1590/1980-54702021v27e0128

DINIZ, D. Zika: do sertão nordestino à ameaça global. 1. ed. Rio de Janeiro, RJ: Civilização brasileira, 2016. 192 p.

FERNANDES, M. P.; SANTOS, S. R.; MERCADO, F. M. O desenvolvimento do brincar em Crianças com a Síndrome Congênita do Zika Vírus. Revista Entreideias, v. 8, n. 2, p. 51-74, maio/ago. 2019. DOI: http://dx.doi.org/10.9771/re.v8i2.27630

FREITAS, D. A. et al. Congenital Zika syndrome: A systematic review. PLoS One, v. 15, n. 12, 2020. DOI: https://doi.org/10.1371/journal.pone.0242367 
FLEISCHER, S.; LIMA, F. (org.). Micro: contribuições da antropologia. Brasília, DF: Athalaia, 2020.

LIMA, T. J.; SOUZA, L. E. C. O papel da autoeficácia parental na saúde mental de mães de crianças com Síndrome da Zika Congênita. Ciência e Saúde Coletiva, v. 26, n. 1, p. 359-368, 2021. DOI: https://doi.org/10.1590/1413-81232020261.02222019

LOPES, M. M. E. et al. Infants Exposed to Zika Virus In Utero. N Engl J Med., v. 379, n. 24, p. 2377-2379. DOI: 10.1056/NEJMc1800098

LÖWY, I. Zika no Brasil: história recente de uma epidemia. Rio de Janeiro, RJ: Editora Fiocruz, 2019.

MACIVER, D. et al. Participation of children with disabilities in school: A realist systematic review of psychosocial and environmental factors. PLoS ONE, v. 14, n. 1, 2019. DOI: https://doi.org/10.1371/journal. pone.0210511

\section{MOREIRA, F. D. S. Recursos e estratégias táteis para crianças com deficiência múltipla} sensorial visual. Editora CRV, 2021.

GRANLUND, M. et al. Differentiating Activity and Participation of Children and Youth with Disability in Sweden a Third Qualifier in the International Classification of Functioning, Disability, and Health for Children and Youth? American Journal of Physical Medicine \& Rehabilitation, v. 91, n. 2 (Suppl), fev. 2012. DOI:

https://doi.org/10.1097/PHM.0b013e31823d5376

MAXWELL, G.; KOUTSOGEORGOU, E. Using Social Capital to Construct a Conceptual International Classification of Functioning, Disability, and Health Children and Youth VersionY Based Framework for Stronger Inclusive Education Policies in Europe. American Journal of Physical Medicine \& Rehabilitation, v. 91, n. 1 (Suppl), jan. 2012. DOI: https://doi.org/10.1097/PHM.0b013e31823d4b92

MARÇAL, C. D. de C. Design participativo e princípios inclusivos: múltiplos modos de mediações na relação de sujeitos com autismo. 2018. 155 f. Tese (Doutorado Em Artes e Design) - Pontifícia Universidade Católica do Rio de Janeiro, 2018.

MARÇAL, C. D. C. Metodologia Caixa e Bacia e sua contribuição às oficinas integradas Zika: centralidade na construção de vínculos entre familiares e profissionais por meio da produção conjunta de objetivos de estimulação par ao desenvolvimento infantil. In:

PENELLO. L. M., LUGARINHO; P. L. M. (Org.). Uma trajetória do cuidado II: resultados e desafios das ações de qualificação para atenção integral às crianças com SCZV e STORCH e suas famílias no âmbito do Sistema Único de Saúde. Rio de Janeiro, RJ: Fiocruz, 2019. p. 53-69.

MARÇAL, C. D. C. Objetos sensoriais para mediação de crianças com deficiência.

Departamento de Artes \& Design PUC-Rio. Disponível em: http://semanadesign.dad.pucrio.br/deriva/SemanaDesign/projeto_18.html. Acesso em: 10 jul. 2021. 
MENEZES, A. et al. Microcefalia relacionada ao vírus Zika e dinâmica familiar: perspectiva da mãe. Av Enferm, v. 37, n. 1, p. 38-46, 2019. DOI:

https://doi.org/10.15446/av.enferm.v37n1.72008

ObEE. Observatório de Educação Especial e Inclusão Educacional. Banco de dados. Nova Iguaçu, RJ, 2019-2020.

PAHO/WHO. Epidemiological Alert Neurological syndrome, congenital malformations, and Zika virus infection. Implications for public health in the Americas. Disponível em: http://www.paho.org/hq/index.php?option=com_docman\&task=doc_download\&Itemid=\&gid $=32405 \&$ lang=en, 2015 . Acesso em: 10 jul. 2021 .

PEÇANHA, P. P. et al. Neurodevelopment of children exposed intra-uterus by Zika virus: A case series. PLoS ONE, v. 15, n. 2, 2020. DOI: https://doi.org/10.1371/journal. pone.0229434

PINTO, M.; FERNANDES, S.; BARROS, L. Estimating the cost of congenital Zika syndrome to families and healthcare providers in Rio de Janeiro and Pernambuco, Brazil: results of a case-control study. Wellcome Open Res, v. 6, n. 28, 2021. DOI: https://doi.org/10.12688/wellcomeopenres.16623.1

PLETSCH, M. D. "Os filhos do Zika Vírus chegaram na escola": Análise dos programas educacionais desenvolvidos nas redes de ensino da Baixada Fluminense. In: Projeto de Pesquisa. Nova Iguaçu, RJ: UFFRJ, 2018.

PLETSCH, M. D. Pesquisas e ações intersetoriais entre educação e saúde na promoção da escolarização e do desenvolvimento de crianças com síndrome congênita do zika vírus na Baixada Fluminense. In: Projeto de Pesquisa. Nova Iguaçu, RJ: UFFRJ, 2019.

PLETSCH, M. D.; MENDES, G. M. L. Entre a espera e a urgência: propostas educacionais remotas para crianças com Síndrome Congênita do Zika Vírus durante a pandemia da COVID-19. Revista Práxis Educativa, Ponta Grossa, v. 15, p. 1-16, 2020. DOI: https://doi.org/10.5212/PraxEduc.v.15.15335.069

PLETSCH, M. D.; ARAUJO, P. C. M. do A.; SOUZA, M. G. de. A importância de ações intersetoriais como estratégia para a promoção da escolarização de crianças com a síndrome congênita do zika vírus (SCZV). In: Educação em Foco, Juiz de Fora, v. 25, n. 3, p. 193-210, set./dez. 2020. DOI: https://doi.org/10.22195/2447-524620202532924

ROSENBAUM. P.; GORTER, J. W. The 'F-words' in childhood disability: I swear this is how we should think! Child Care Health Dev., v. 38, n. 4, p. 457-63, 2012.

DOI: https://doi.org/10.1111/j.1365-2214.2011.01338.x

ROCHA, M. G. de S. da. Processos de ensino e aprendizagem de alunos com múltiplas deficiências no AEE à luz da teoria histórico-cultural. 2014. 233 f. Dissertação (Mestrado em Educação) - Universidade Federal Rural do Rio de Janeiro, Nova Iguaçu, 2014.

ROCHA, M. G. de S. da. Os sentidos e significados da escolarização de sujeitos com deficiência múltipla. 2018. 291 f. Tese (Doutorado em Educação) - Universidade Federal Rural do Rio de Janeiro, Nova Iguaçu, 2018. 
ROCHA, M. G. S.; PLETSCH, M. D. Deficiência múltipla: disputas conceituais e políticas educacionais no Brasil. Cadernos de Pesquisa, São Luís, v. 22, n. 1, p. 112-125, jan./abr. 2015. DOI: http://dx.doi.org/10.18764/2178- 2229.v22.n1.p.112-125

ROCHA, M. G. S.; PLETSCH, M. D. Deficiência múltipla, sistemas de apoio e processos de escolarização. Revista Horizontes, Itatiba, v. 36, n. 3, p. 99-110, set./dez. 2018. DOI: https://doi.org/10.24933/horizontes.v36i3.700

ROCHA, M. G. S.; PLETSCH, M. D. Comunicação alternativa como instrumento externo de compensação: possibilidades para a aprendizagem de alunos com múltiplas deficiências.

Revista Interinstitucional Artes de Educar, v. 4, n. 1. 2018. DOI:

https://doi.org/10.12957/riae.2018.32774

SÁ, M. R. C.; PLETSCH, M. D. A participação de crianças com a Síndrome Congênita do Zika Vírus: intercessões entre o modelo bioecológico e a funcionalidade humana. Práxis Educativa (UEPG. ONLINE), v. 16, p. 1-15, 2021. DOI:

https://doi.org/10.5212/PraxEduc.v.16.17383.017

VIANA, V. D. G. S. M. Educação Especial na perspectiva das Humanidades Digitais: o que dizem os Bancos de dados da Capes e do IBICT sobre a síndrome congênita do zika vírus? 2021. 170 f. Dissertação (Mestrado em Humanidades Digitais) - Universidade Federal Rural do Rio de Janeiro, Nova Iguaçu, 2021.

\section{Como referenciar este artigo}

PLETSCH, M. D.; SÁ, M. R. C.; ROCHA, M. G. S. Tecnologias assistivas para a comunicação e a participação de crianças com a Síndrome Congênita do Zika Vírus. Revista Ibero-Americana de Estudos em Educação, Araraquara, v. 16, n. esp. 4, p. 2971-2989, dez. 2021. e-ISSN: 1982-5587. DOI: https://doi.org/10.21723/riaee.v16iesp.4.16062

Submetido em: 20/08/2021

Revisões requeridas em: 30/10/2021

Aprovado em: 10/12/2021

Publicado em: 30/12/2021 